\title{
Measuring Capability for Healthy Diet and Physical Activity
}

\author{
Robert L. Ferrer, MD, MPH \\ Inez Cruz, MSW \\ Sandra Burge, $P b D^{1}$ \\ Bryan Bayles, $P b D^{1}$ \\ Martha I. Castilla, $\mathrm{CHW}^{2}$ \\ 'Department of Family and Community \\ Medicine, University of Texas Health Sci- \\ ence Center at San Antonio, San Antonio, \\ Texas \\ ${ }^{2}$ Corazon para El Barrio, San Antonio, Texas
}

\begin{abstract}
PURPOSE Patterns of diet and physical activity, major drivers of morbidity and mortality, are contingent on people's feasible opportunities to pursue healthy behaviors. Our objective for this mixed methods study was to develop measures of feasible opportunities for diet and activity.

METHODS The Capability Approach framework for evaluating people's real freedoms to pursue their values guided the research. A community-based participatory model was applied to conduct focus groups of adults with obesity or diabetes mellitus from an economically disadvantaged Latino community. Focus group themes were developed into survey items that assess how individual circumstances and neighborhood contexts influence opportunities for diet and activity. The prevalence of different influences was explored in a sample of 300 patients from a primary care safety net clinic. Scales measuring different aspects of opportunity were created through principal components analysis.
\end{abstract}

RESULTS Availability, convenience, safety, cost of food, and activity resources interact with individual circumstances, such as illness, depression, family and nonfamily supports, and scope of personal agency, to shape practical opportunities. Multiple vulnerabilities in availability of resources and moderators of resource use commonly occur together, intensifying challenges and creating difficult trade-offs. Only one-half of participants reported that physicians understood their difficulties pursuing activity, and just one-third for diet.

CONCLUSIONS Our results suggest that practical opportunities for healthy behavior can be measured as a primary target for clinical and public health assessment and intervention. The Capability Approach holds promise as a framework for developing interventions responsive to both personal and environmental determinants.

Ann Fam Med 2014;46-56. doi:10.1370/afm.1580

\section{INTRODUCTION}

U nhealthy diet and sedentary living cause substantial morbidity and mortality in developed societies, ${ }^{1,2}$ taking their greatest toll on disadvantaged populations. ${ }^{3-9}$ These behaviors have proved difficult to manage in both clinica ${ }^{10}$ and public health ${ }^{11}$ contexts because they have complex roots at the interface between individual choices and social and physical environments. ${ }^{12-14}$

Given primary care's high contact rate with disadvantaged populations $^{15}$ and the importance of health behaviors in managing chronic diseases ${ }^{16}$ addressing behaviors is an essential function..$^{17,18}$ But its performance in this role has been mixed: a large, complex literature reports only modest success in improving diet and physical activity. ${ }^{10,19-22}$ Primarily, interventions have focused on increasing individuals' knowledge, motivation, and self-efficacy. ${ }^{23}$

Much evidence shows, however, that success will be limited if social and environmental contexts are not accounted for. ${ }^{24-31}$ Even so, the clinician's task involves more than acknowledging context ${ }_{\text {; }}$ the challenge is to understand how to help a specific patient succeed in a specific environment. The ubiquity of behavioral risk factors in primary care makes this high-volume 
task a high priority, ${ }_{1}^{32}$ yet primary care clinicians lack a systematic method to manage it. To address this gap, we operationalize a conceptual approach ${ }^{33}$ to managing the complex challenges of health behaviors, beginning with measurement tools to help practices determine which patients have limited opportunities for healthy living. We describe the initial qualitative and quantitative findings from instrument development.

\section{METHODS}

\section{Conceptual Development}

Developed in welfare economics, the Capability Approach $^{34,35}$ is an analytical framework for individual and social well-being that focuses on the practical opportunities (capabilities) people have to achieve the goals they value. ${ }^{36}$ What distinguishes the CA from traditional evaluations is that it examines not only a person's attainment of important outcomes but also the feasible opportunities to do so. ${ }^{37}$ Focusing on opportunity reveals how behavior is constrained by personal or environmental circumstances, disentangling the contextual question of whether there are real opportunities to make good choices from the behavioral question of whether a good choice is made. ${ }^{38}$ When evaluating capabilities, 2 aspects must be distinguished: the agency aspect (the power to make one's own choices) and the opportunity aspect (having adequate opportunities to choose from). ${ }^{39}$

Determinants of capability include (1) inputs, such as available goods and services and the purchasing power to access them; and (2) conversion factors that moderate a person's ability to turn available goods and services into real opportunities, such as personal conversion factors (eg, physical disability, literacy), social conversion factors (social norms, discrimination, other power relationships), and environmental conversion factors (relevant features of the built and physical environment). ${ }^{40}$ These determinants shape the capability set, the array of feasible opportunities that are within a person's reach.

\section{Overall Approach}

Using Loevinger's framework for instrument development ${ }^{41}$ we addressed substantive validity by defining constructs through focus groups and created the survey questionnaire items from the emergent themes. We then assessed the questionnaire's structural validity by constructing scales and evaluating their internal consistency and homogeneity.

\section{Phase 1: Qualitative Study}

In phase 1, we analyzed focus group data from a community sample of persons with obesity and diabetes mellitus, choosing these conditions because healthy diet and activity would be expected to be clinically relevant. Using a community-based participatory research model ${ }_{1}^{42}$ we partnered with a grass-roots service organization, the Edgewood Family Network (EFN), to design and conduct the study and analyze data. EFN serves an economically disadvantaged, primarily Latino area of west San Antonio with a high prevalence of obesity and diabetes. Qualitative data were collected in 2010.

We used EFN promotores (Latino lay community health workers) to purposively sample 145 adults who were obese or had diabetes mellitus from the network of families they serve, forming 14 groups, respecting preferences for language (English or Spanish) and same-sex or mixed groups. We chose the number of groups conservatively, erring towards greater data gathering. ${ }^{43}$

Inclusion criteria included aged 18 years or older, English or Spanish speaking, living in EFN's service area, and having a diagnosis of type 2 diabetes (selfreport) or obesity. We excluded persons with cognitive impairment precluding focus group participation.

Focus groups lasting approximately 90 minutes were conducted by study investigators and promotores trained in qualitative methods.

In cooperation with the EFN promotores, we developed an interview guide with 4 main questions: (1) What are your values and goals for staying healthy? (2) What resources for healthy living are available in your community? (3) What helps or hinders turning those resources into real opportunities? (4) Do your goals change when there are few opportunities? How so?

The analysis used the framework approach, suitable for applied research with prespecified objectives. ${ }^{44}$ Focus group meetings were audiotaped and transcribed, then translated, if necessary. Two investigators (B.B. and R.L.F.) used Atlas.ti software ${ }^{45}$ to iteratively code text, independently identifying key terms and themes and then reviewing transcripts to reach consensus on significant concepts, as well as unanticipated issues, raised by the participants. To promote reliability, the investigative team and promotores developed a coding dictionary.

\section{Phase 2: Quantitative Study}

Phase 2 was a structured survey conducted in 2011. We developed the items from focus group themes, aiming for at least 10 candidate items per theme. A 5-point Likert response set for each item ranged from strongly disagree to strongly agree. We iteratively tested a preliminary pool of 120 items in cognitive interviews with members of the target clinical population to identify and edit potentially misunderstood items. The resulting questionnaire was then translated into Spanish and 
evaluated for conceptual equivalence. The final version was reevaluated and approved by the promotores.

A research associate recruited 300 survey respondents from a safety-net primary care practice. Eligibility criteria included age 18 years or older, diagnosis of either obesity or diabetes mellitus (self-reported), ability to read English or Spanish, and lack of cognitive impairment.

The survey objective was to estimate prevalences for resources and conversion factors and to generate preliminary scales measuring Capability Approach constructs. For the latter, we applied principal components analysis (using Stata 11, StataCorp LP) to reduce the candidate items, examining eigenvalues, factor loadings, and factor correlations to arrive at a best factor solution. Missing value frequencies were less than 5\% across the survey items.

The study was approved by the Institutional Review Board at the University of Texas Health Science Center at San Antonio.

\section{RESULTS}

\section{Phase 1 Focus Group Study}

Participants included 109 women and 36 men, all Latino. Their mean age was 47 years (range 19 to 79 ). Spanish was the principal language for $62 \%$. Diabetes was the primary inclusion criterion for $40 \%$ of the sample, and obesity for $60 \%$.

\section{Agency: Goals, Values, Motivation, and Choice} Participants endorsed healthy diet and adequate physical activity as valued goals. Most often participants specified children as their primary motive for wanting better health. Perceiving themselves as being at high risk from diabetes and its complications, and having witnessed close relatives struggle with those illnesses, they feared burdening their families.

Yet participants acknowledged that their behavior often fell short of their ideals. Reasons for not following through included work-related fatigue, household chores, and time pressures from juggling responsibilities. Depression was often mentioned as an inhibitor of motivation, as well as a trigger for unhealthy behavior: "Depression a lot of times because you can't pay your bills because you don't have enough, that depresses you, that makes you eat, that makes you do things that you shouldn't." Physical illness also had a complex relationship with behavior, motivating changes yet giving rise to functional limitations that hindered it.

Participants described limited autonomy. Disempowerment in domestic relationships arose when male partners discouraged or prohibited women from preparing healthier meals or leaving the home for physical activity. "Not my husband. He tells me that the one on a diet is you not me." Outside the home, disempowerment occurred through exposure to institutional mistreatment. "The receptionist...asked for [his] social security card and...she asked him where he had purchased it."

A few respondents bluntly characterized their behavior as "lazy," often in the context of watching Spanish-language serials, the telenovelas. They also noted, however, that viewing these popular programs was part of participating in the social life of their community.

\section{The Intersection of Personal and Community Resources}

Participants identified the presence, convenience, and cost of community resources as important determinants of health behaviors. Although participants sometimes framed them in absolute terms, such as the absence of a park, they more commonly described resources' utility relative to their own circumstances. Reaching a park, for example, could depend on having a personal vehicle, a connecting bus route, or a bus stop with adequate seating for those unable to stand for long periods.

Programmatic subsidies were important contributions for access to such services as gym memberships, recreation programs, and health care, without which those services were often perceived as out of reach. Participants recognized value of subsidies, yet enrollment procedures for means-tested programs could be demeaning ordeals. Participants described carefully vetting the resources' costs, means testing, and whether undocumented persons were excluded.

\section{The Importance of Conversion Factors}

Conversion factors moderated participants' ability to convert resources into feasible opportunities. Some participants needed additional information to move from general notions about healthy behaviors to specific activity patterns.

So then, there is where they also disappoint us and start with what one already knows, that you're not supposed to drink the glass of juice, you can't drink the coke, the tortillas. Well, we already know that. ... I would like for them to say, [how] they would switch the food, how to make the food.

Family support occurred through encouraging behavior change, modeling behavior, or coparticipating in structured activities. Family responsibilities of caring for children or infirm relatives could also limit opportunities. "You can't go exercise because you're taking care of someone for being ill. Sometimes you put your whole life on hold to take care of someone." 
Support from outside the family was critical for many participants. Friends provided motivation or companionship for healthy activities. Group activities with peers were highly valued.

Participants' own sense of not living up to social norms - manifested as shame-could restrict their activities outside the home:

A: Because sometimes you don't want to go alone.

A: Yes, well, that's true if someone's ashamed.

Q: Of what?

A: To just go. To go and have someone see you doing exercises.

\section{Alignment of Multiple Vulnerabilities}

Examining opportunities one at a time fails to capture the multidimensional nature of constraints that limit opportunities: "Q: Why can't you go walking? A: Because I don't know how to drive." Here a middleaged woman's opportunity for physical activity is limited by not having a driver's license, a neighborhood too unsafe to walk alone, no available companions for physical activity or nearby gyms that she can afford, and no public transportation to link her with a walkable destination.

\section{Phase 2 Capability Survey}

Survey participation rate was $95 \%$. The 300 respondents yielded 292 usable questionnaires. Respondents (Table 1) ranged in age from 18 to 78 years; $78 \%$ were female, $82 \%$ Hispanic, and $12 \%$ African American. Only $35 \%$ had schooling beyond high school. More than 50 metropolitan zip codes were represented.

We initially analyzed questionnaire items under 2 headings: resources and conversion factors, calculating percentages (Figures 1 and 2) of those who agreed or strongly agreed with a given statement. To frame all items in the direction of greater opportunity, coding was reversed for items measuring barriers.

Opportunities for food shopping were rated highly, with $96 \%$ reporting fruits and vegetables sold where they shop, and $86 \%$ reporting easy travel to a food market. Food insecurity was common, however, with many respondents identifying trade-offs between food and other necessities, and $71 \%$ reporting they could not afford groceries for an entire month. With respect to physical activity, $72 \%$ of respondents noted nearby opportunities for outdoor activity, though only $27 \%$ felt safe walking after dark. One-half reported indoor physical activity was available nearby. Only 20\% said they could afford a gym.

Following the lead of the focus groups, we evaluated conversion factors, including (self-perceived) health literacy, support from family and friends, house- hold power relationships, professional support, social norms, fatigue, and depression, almost all of which reduced opportunities for more than $20 \%$ of the sample. Exceptions included physician encouragement for healthy diet and activity, each reported by more than $90 \%$ of respondents. Much lower percentages reported that physicians understood their difficulties in pursuing health behaviors, however: slightly more than one-half for physical activity and barely one-third for diet.

Survey responses confirmed focus group accounts of domestic partners undermining healthy behaviors, with $14 \%$ reporting sometimes being forbidden to pursue physical activity, $18 \%$ considering jealousy when planning activities, and $31 \%$ facing refusals to eat healthier meals. Those barriers were reported by similar proportions of men and women. One-half the participants, however, noted the opposite, that partners aided healthy behaviors.

Not surprisingly in a sample with high rates of obesity and diabetes mellitus, 59\% of respondents said poor health limited their physical activity.

Multiple vulnerabilities appeared in the survey data as well. For example, when examining 4 physical activity questions ( 2 resources: feeling safe in neighborhood after dark, having indoor places for physical activity; and 2 conversion factors: partner support for physical activity, and friends' company for physical activity), we found that $48 \%$ of respondents reported only 0 or 1 of those opportunities present.

After examining eigenvalues, factor loadings, and factor correlations, we found that the best solution in

Table 1. Sample Characteristics

\begin{tabular}{lc}
\hline Characteristic & Value \\
\hline Sample size, No. & 292 \\
Age, mean (range), y & 46.8 (18-78) \\
Female, \% & 78 \\
Race/ethnicity, \% & \\
Hispanic & 81.5 \\
Non-Hispanic black & 8.9 \\
Non-Hispanic white & 7.9 \\
Other & 1.7 \\
Survey language, \% & 82.3 \\
English & 17.7 \\
Spanish & \\
Educational attainment, \% & 15.0 \\
0-8 years & 19.7 \\
$9-11$ years & 30.3 \\
High school graduate/GED & 35.0 \\
Any college & 96 \\
BMI >25 kg/m², \% & 56.6 \\
Diabetes mellitus, \% & \\
\hline BMI = body mass index; GED = general equivalency diploma. \\
\hline
\end{tabular}




\section{Figure 1. Prevalence of resources.}

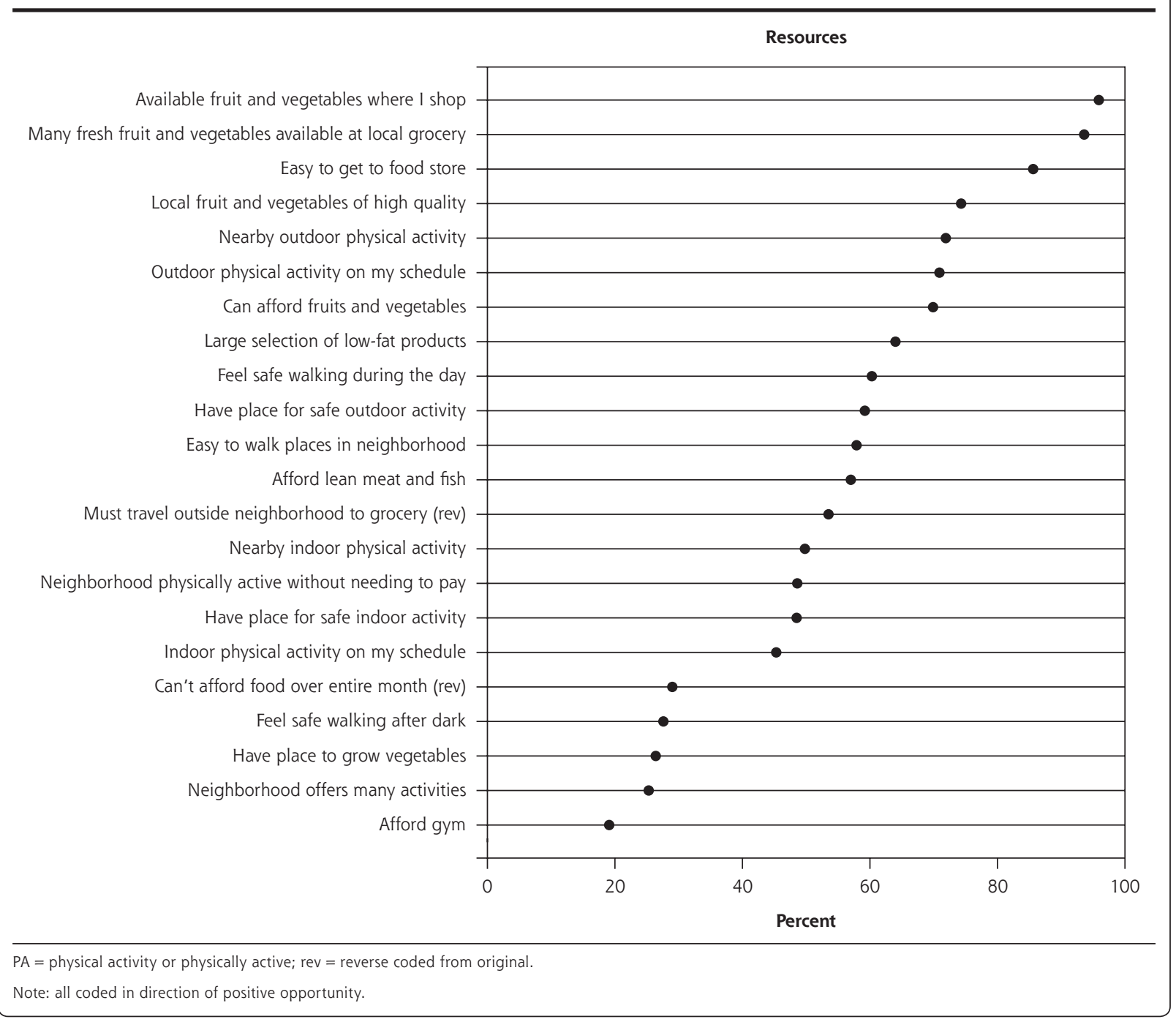

a principal components analysis contained 8 factors, with an overall Cronbach's $\alpha$ of .86. The Kaiser-MeyerOlkin measure of sampling adequacy for the whole instrument is .77. Subscale $\alpha$ levels range from .62 to .83. The items group into 2 subscales for resources (convenient resources, neighborhood opportunities) and 6 subscales for conversion factors (barriers, knowledge, available time, family support, spouse/partner support, and nonfamily support). The items, scales, factor loadings, and $\alpha$ levels appear in Table 2. We also evaluated items' loading if diet and activity were factored separately. Loadings were similar for all but a few items.

Finally, to analyze the multidimensional aspect of resources and conversion factors, we examined the covariance of summary resource and conversion factor scales for diet or physical activity (Figure 3). The strongest correlations appear between diet and activity resources and between diet and activity conversion factors. Figure 4 displays multidimensional scores on these 4 scales for 60 randomly selected participants. These plots can be read as graphical summaries of individuals' resources and conversion factors for diet and activity. Comparing plots shows the considerable interindividual variability in capability. Notably, many of the plots display symmetrical shrinkage, indicating that individuals face limitations on all 4 scales.

\section{DISCUSSION}

This mixed methods study assessed practical opportunities for healthy diet and activity in a socioeconomically disadvantaged population. Focus groups and survey data identified important resources and moderators shaping opportunities. Together, these data make a compelling case for practical opportunities as a primary target for clinical and public health assess- 
ment and intervention. Given the geographic, ethnic, and socioeconomic homogeneity of the sample, the survey findings revealed a wide range of opportunity, driven by variations in neighborhood environments, physical and mental health status, family composition, family and peer support, and personal autonomy. This variability indicates it is important not to make assumptions about what is feasible for a given person. ${ }^{46}$
Systematic assessment of how personal circumstances interact with resources in the environment is needed to understand the different supports needed by different people to create the same substantive opportunity.

Our focus group and survey data confirmed the importance of assessing both agency to choose and adequacy of available opportunities. Distinguishing between them is important because the solutions

Figure 2. Prevalence of conversion factors.

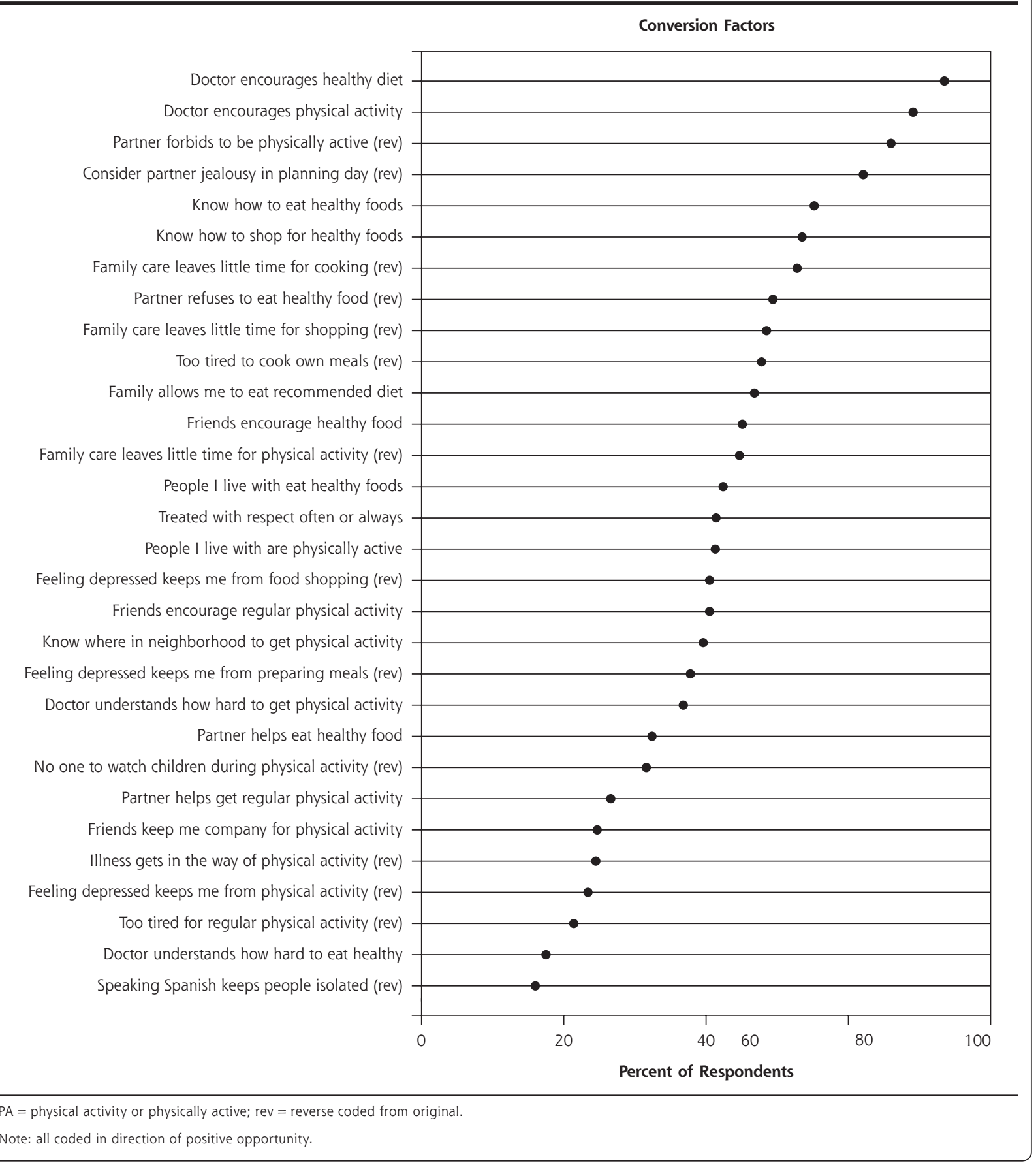

ANNALS OF FAMILY MEDICINE + WWW.ANNFAMMED.ORG + VOL. 12, NO. 1 + JANUARY/FEBRUARY 2014 
Table 2. Capability Assessment for Diet and Activity (CADA)

\begin{tabular}{|c|c|c|c|}
\hline Subscale & Item & Load $^{\mathrm{a}}$ & Diet/Activity ${ }^{b}$ \\
\hline Convenience, cost & Easy to get to store for food shopping & 0.64 & $\mathrm{D}$ \\
\hline \multirow[t]{6}{*}{$\alpha=.78$} & Nearby places for outdoor physical activity & 0.52 & A \\
\hline & Places open when I want to do indoor physical activity & 0.49 & A \\
\hline & Fresh fruits and vegetables available where I shop for food & 0.74 & $\mathrm{D}$ \\
\hline & I can afford to buy fresh fruits and vegetables & 0.57 & $\mathrm{D}$ \\
\hline & I can afford to buy fish or lean meat & 0.52 & $\mathrm{D}$ \\
\hline & Fruits and vegetables where I shop are high quality & 0.57 & $\mathrm{D}$ \\
\hline \multirow{5}{*}{$\begin{array}{l}\text { Neighborhood opportunity } \\
\quad \alpha=.78\end{array}$} & In my neighborhood it is easy to walk places & 0.72 & A \\
\hline & Places where I can be active without needing to pay & 0.65 & A \\
\hline & I often see other people walking in my neighborhood & 0.71 & A \\
\hline & People generally feel safe in my neighborhood & 0.64 & A \\
\hline & My neighborhood is well lighted for evening activities & 0.59 & A \\
\hline \multirow{5}{*}{$\begin{array}{l}\text { Barriers } \\
\alpha=.75\end{array}$} & I am too tired to be physically active & 0.62 & \\
\hline & Illness gets in the way of cooking own meals & 0.71 & D \\
\hline & I am too tired to cook my own meals & 0.76 & $\mathrm{D}$ \\
\hline & Feeling depressed keeps me from being active & 0.74 & A \\
\hline & Feeling depressed keeps me from shopping for food & 0.72 & $\mathrm{D}$ \\
\hline \multirow{3}{*}{$\begin{array}{c}\text { Knowledge } \\
\alpha=.83\end{array}$} & I know how to eat healthy foods & 0.89 & $\mathrm{D}$ \\
\hline & When I eat at a restaurant I know how to choose a healthy meal & 0.86 & $\mathrm{D}$ \\
\hline & I know where in my neighborhood to shop for healthy foods & 0.75 & $\mathrm{D}$ \\
\hline \multirow{5}{*}{$\begin{array}{l}\text { Time pressure } \\
\alpha=.75\end{array}$} & Taking care of my family gives little time to be physically active & 0.55 & A \\
\hline & Taking care of my family gives me little time to cook meals & 0.51 & $\mathrm{D}$ \\
\hline & My schedule gives me little time to cook my own meals & 0.85 & $\mathrm{D}$ \\
\hline & My schedule gives me little time to go food shopping & 0.85 & $\mathrm{D}$ \\
\hline & I have time to be physically active on most days & 0.54 & \\
\hline \multirow{3}{*}{$\begin{array}{l}\text { Family support } \\
\qquad \alpha=.62\end{array}$} & There are people I live with who eat healthy foods & 0.77 & $\mathrm{D}$ \\
\hline & There are people I live with who are physically active & 0.75 & \\
\hline & Family allows me to eat recommended foods & 0.59 & \\
\hline \multirow{3}{*}{$\begin{array}{l}\text { Spouse/partner } \\
\qquad \begin{array}{l}\alpha=.65\end{array}\end{array}$} & Spouse or partner complains when I serve a healthy meal & 0.44 & $\mathrm{D}$ \\
\hline & Spouse or partner doesn't allow me to be physically active & 0.81 & \\
\hline & When I plan my day, I have to think about my partner's jealousy & 0.78 & \\
\hline \multirow{3}{*}{$\begin{array}{l}\text { Nonfamily support } \\
\qquad \alpha=.80\end{array}$} & Friends encourage me to be physically active & 0.84 & \\
\hline & Friends encourage me to eat healthy foods & 0.87 & \\
\hline & Friends keep me company when I'm physically active & 0.70 & A \\
\hline
\end{tabular}

are different: empowerment in one case, increasing available resources in the other. Respondents more commonly reported limitations in opportunity rather than agency. Notably, in focus groups only women described limited agency, whereas when surveyed, both sexes reported it equally. The discrepancy may be due to men's reticence to openly disclose limited agency.

Qualitative and quantitative data also converge on other findings. Limited household and community resources create strong demand for positive supports, yet participants noted that institutions and businesses often fail to meet their needs. To the extent that healthy foods and activity venues are commodities, poor communities offer few incentives. Participants understood this scarcity, and focus groups contained many instances in which participants avidly inquired about services that others had successfully accessed. This communication channel, the social network, can potentially be leveraged to diffuse knowledge about local assets through trusted sources. The limits of commodity approaches also highlight the critical role of public goods-communal spaces, for example-in supporting healthy behaviors.

Mindfulness of opportunity's multidimensional nature is critical for success. The joint distributions of resources and conversion factors for diet and physical activity confirm that multiple opportunity deprivations are common. Obstacles can therefore be underestimated if they are considered in isolation. The correlations also suggest, however, that addressing such 
conversion factors as depression, literacy, or autonomy for one health behavior may have a positive effect on other behaviors. Typically, these problems would be addressed through distinct interventions, but it may be fruitful to consider place-based approaches that engage local populations in solving multiple problems. ${ }^{47}$

Considering the many achievements that people value and attempt to balance helps explain certain trade-offs and paradoxes in health behaviors. One such paradox is the coexistence of food insecurity and obesity as families use their limited funds to buy densely caloric foods. Another is illustrated by the accounts of those who avoid outdoor activities they feel would open them up to public shame.

Although many studies, qualitative ${ }^{48-52}$ and quantitative, ${ }^{53-56}$ have investigated facilitators and barriers for health behaviors, the Capability Approach addresses persistent challenges in the field. ${ }^{57}$ Two large bodies of health behavior research-one focusing on individuals' choices and another on environmental contexts-have been largely unconnected. To remedy the divide, a set of ecological models emerged ${ }^{58-60}$ that encompass individual and social determinants, yet it remains unclear how these models should influence clinical practice. The models list influences at multiple levels without offering a clear picture of how they might come together for a given individual. The Capability Approach, providing a synthesis of resources, conversion factors, and practical opportunities, points a way forward. It helps disentangle the problem of behavior change in disadvantaged populations into a set of components to be managed. Measuring capabilities in primary care would help identify subsets of patients with relatively better and worse capabilities, so resources could be directed toward the latter.

Helping these identified patients develop workable opportunities calls for appropriate systems of care. ${ }^{61}$ The essential

Note: Individual plots display 4 measures on 4 separate axes: scale scores for diet resources (north); diet conversion factors (east); activity resources (south); and activity conversion factors (west). Each scale's range is 1 (center) to 5 (periphery). At bottom right is displayed the plot resulting from a maximum score on each measure. 
core functions include assessing patients' capabilities in a standardized format, reviewing data, and connecting vulnerable patients with interventions. Depending on practice size and setting, these responsibilities could be carried out by trained medical assistants, health educators, nurse care managers, or software systems. In many areas, community health workers are available to assist patients with activation, problem solving, and navigation to needed resources. Although core functions will usually depend on personnel other than the primary care clinician, the gaps our survey respondents noted in clinicians' understanding of their health behavior challenges suggest that clinicians' behavioral counseling would also be improved by these data.

For communities, systematically assessing capabilities can help explain and address the prevalence of unhealthy behaviors. In our local work, the Capability Approach has helped structure policy conversations that emphasize the limitations of personal choice as the principal intervention target, while presenting an actionable alternative: expanding people's practical opportunities. Many communities will require substantial multisectoral work to improve their food and activity environments, but federal initiatives, such as Communities Putting Prevention to Work and Community Transformation Grants, are providing critical support for local efforts to create the conditions for healthy living. ${ }^{62}$ There is growing consensus that the public health and clinical endeavors promoting health behavior change would benefit from greater coordination. ${ }^{63}$

The study is subject to several limitations. We studied a single ethnic group in one community, so results may not be generalizable to other areas, particularly where the relationship between personal and contextual disadvantage differs. With little income or racial/ethnic heterogeneity in the sample, we were unable to examine how these variables influenced capability. Also, we began with a predefined analytical framework. Although our analysis was open to unexpected findings, a grounded theory methodology might have yielded alternative interpretations. We had difficulty addressing one of our primary questions, whether people adjust their health goals downward when they see few opportunities to achieve them. Respondents appeared to have difficulty with the question's premise or with imagining the counterfactual where opportunities were abundant. Finally, this preliminary evaluation did not assess survey reliability or construct validity. A larger study, in progress, is evaluating capability for diet and physical activity simultaneously with measures of those behaviors.

Strengths included a community-based participatory research design with our community partner involved in planning, focus group development, recruitment, and interpretation. The many focus groups increased our confidence that we had adequately sampled different experiences. Offering focus groups and questionnaires in English and Spanish gathered perspectives across levels of acculturation.

Our results suggest that practical opportunities for healthy diet and physical activity can be measured as a primary target for clinical and public health assessment, with the potential to help align multilevel interventions and close the gap between intention and achievement.

To read or post commentaries in response to this article, see it online at www.annfammed.org/content/12/1/46.

Key words: health behaviors; models, theoretical; social environment; qualitative research

Submitted April 27, 2013; submitted, revised, March 17, 2013; accepted April 5, 2013.

Funding support: This project was supported by grant number R03HS017974 from the Agency for Healthcare Research and Quality.

Disclaimer: The content is solely the responsibility of the authors and does not necessarily represent the official views of the Agency for Healthcare Research and Quality.

Previous presentations: Portions of the data were presented at the North American Primary Care Research Group 39th Annual Meeting, Banff, Canada, November 11-16, 2011 and 40th Annual Meeting, New Orleans, La, December 1-5, 2012.

Acknowledgment: We thank the Promotores de Buena Vida of the Edgewood Family Network, Marisela Castilla, Eustolia Santos, and Lucia Ayala for their valued collaboration on this project.

\section{References}

1. Mokdad AH, Marks JS, Stroup DF, Gerberding JL. Actual causes of death in the United States, 2000. JAMA. 2004;291(10):1238-1245.

2. Beaglehole R, Bonita R, Horton R, et al; Lancet NCD Action Group; NCD Alliance. Priority actions for the non-communicable disease crisis. Lancet. 2011;377(9775):1438-1447.

3. Smith JP. Nature and causes of trends in male diabetes prevalence, undiagnosed diabetes, and the socioeconomic status health gradient. Proc Natl Acad Sci U S A. 2007;104(33):13225-13231.

4. Miech RA, Kim J, McConnell C, Hamman RF. A growing disparity in diabetes-related mortality U.S. trends, 1989-2005. Am J Prev Med. 2009;36(2):126-132.

5. Singh GK, Siahpush M, Kogan MD. Rising social inequalities in US childhood obesity, 2003-2007. Ann Epidemiol. 2010;20(1):40-52.

6. Hill JO. Understanding and addressing the epidemic of obesity: an energy balance perspective. Endocr Rev. 2006;27(7):750-761.

7. Darmon N, Drewnowski A. Does social class predict diet quality? Am J Clin Nutr. 2008;87(5):1107-1117.

8. Kruger J, Kohl HW III, Miles IJ; Centers for Disease Control and Prevention (CDC). Prevalence of regular physical activity among adults-United States, 2001 and 2005. MMWR Morb Mortal Wkly Rep. 2007;56(46):1209-1212. 
9. Krieger N, Rehkopf DH, Chen JT, Waterman PD, Marcelli E, Kennedy $M$. The fall and rise of US inequities in premature mortality: 1960-2002. PLoS Med. 2008;5(2):e46.

10. Lin JS, O'Connor E, Whitlock EP, Beil TL. Behavioral counseling to promote physical activity and a healthful diet to prevent cardiovascular disease in adults: a systematic review for the U.S. Preventive Services Task Force. Ann Intern Med. 2010;153(11):736-750.

11. Verheijden MW, Kok FJ. Public health impact of community-based nutrition and lifestyle interventions. Eur J Clin Nutr. 2005;59(Suppl 1):S66-S75, discussion $\mathbf{S 7 6 .}$

12. Brownell KD, Kersh R, Ludwig DS, et al. Personal responsibility and obesity: a constructive approach to a controversial issue. Health Aff (Millwood). 2010;29(3):379-387.

13. Navarro AM, Voetsch KP, Liburd LC, Giles HW, Collins JL; National Expert Panel on Community Health Promotion. Charting the future of community health promotion: recommendations from the National Expert Panel on Community Health Promotion. Prev Chronic Dis. 2007;4(3):A68.

14. Candib LM. Obesity and diabetes in vulnerable populations: reflection on proximal and distal causes. Ann Fam Med. 2007;5(6): 547-556.

15. Ferrer RL. Pursuing equity: contact with primary care and specialist clinicians by demographics, insurance, and health status. Ann Fam Med. 2007;5(6):492-502.

16. Orchard TJ, Temprosa M, Goldberg R, et al; Diabetes Prevention Program Research Group. The effect of metformin and intensive lifestyle intervention on the metabolic syndrome: the Diabetes Prevention Program randomized trial. Ann Intern Med. 2005;142(8):611-619.

17. Estabrooks PA, Glasgow RE, Dzewaltowski DA. Physical activity promotion through primary care. JAMA. 2003;289(22):2913-2916.

18. Green LA, Cifuentes M, Glasgow RE, Stange KC. Redesigning primary care practice to incorporate health behavior change: prescription for health round-2 results. Am J Prev Med. 2008;35(5)(Suppl): S347-S349.

19. Eden KB, Orleans CT, Mulrow CD, Pender NJ, Teutsch SM. Does counseling by clinicians improve physical activity? A summary of the evidence for the U.S. Preventive Services Task Force. Ann Intern Med. 2002;137(3):208-215.

20. Goldstein MG, Whitlock EP, DePue J; Planning Committee of the Addressing Multiple Behavioral Risk Factors in Primary Care Project. Multiple behavioral risk factor interventions in primary care. Summary of research evidence. Am J Prev Med. 2004;27(2)(Suppl):61-79.

21. van Sluijs EM, van Poppel MN, van Mechelen W. Stage-based lifestyle interventions in primary care: are they effective? Am J Prev Med. 2004;26(4):330-343.

22. Orrow G, Kinmonth AL, Sanderson S, Sutton S. Effectiveness of physical activity promotion based in primary care: systematic review and meta-analysis of randomised controlled trials. BMJ. 2012;344:e1389.

23. Elder JP, Ayala GX, Harris S. Theories and intervention approaches to health-behavior change in primary care. Am J Prev Med. 1999; 17(4):275-284.

24. Brownson RC, Baker EA, Housemann RA, Brennan LK, Bacak SJ. Environmental and policy determinants of physical activity in the United States. Am J Public Health. 2001;91(12):1995-2003.

25. Giles-Corti B, Donovan RJ. The relative influence of individual, social and physical environment determinants of physical activity. Soc Sci Med. 2002;54(12):1793-1812.

26. Baranowski T, Cullen KW, Nicklas T, Thompson D, Baranowski J. Are current health behavioral change models helpful in guiding prevention of weight gain efforts? Obes Res. 2003;11(October)(Suppl): 235-435.

27. Gordon-Larsen $\mathrm{P}$, Nelson MC, Page P, Popkin BM. Inequality in the built environment underlies key health disparities in physical activity and obesity. Pediatrics. 2006;117(2):417-424.
28. Ford PB, Dzewaltowski DA. Disparities in obesity prevalence due to variation in the retail food environment: three testable hypotheses. Nutr Rev. 2008;66(4):216-228.

29. Guide to Community Preventive Services. Environmental and policy approaches: street-scale urban design and land use policies $\&$ practices. http://www.thecommunityguide.org/pa/environmental-policy/ streetscale.html.

30. van der Horst K, Oenema A, Ferreira I, et al. A systematic review of environmental correlates of obesity-related dietary behaviors in youth. Health Educ Res. 2007;22(2):203-226. http://www.her.oxfordjournals.org/cgi/doi/10.1093/her/cyl069.

31. Woolf SH, Dekker MM, Byrne FR, Miller WD. Citizen-centered health promotion: building collaborations to facilitate healthy living. Am J Prev Med. 2011;40(1)(Suppl 1):S38-S47.

32. Pronk NP, Peek CJ, Goldstein MG. Addressing multiple behavioral risk factors in primary care. A synthesis of current knowledge and stakeholder dialogue sessions. Am J Prev Med. 2004;27(2)(Suppl):4-17.

33. Ferrer RL, Carrasco AV. Capability and clinical success. Ann Fam Med. 2010;8(5):454-460.

34. Ruger JP. Health capability: conceptualization and operationalization. Am J Public Health. 2010;100(1):41-49.

35. Sen A. Inequality Reexamined. Oxford: Oxford University Press; 1992.

36. Sen AK. Commodities and Capabilities. North-Holland Amsterdam; 1985.

37. Sen A. Development as Freedom. New York, NY: Alfred A. Knopf; 1999.

38. Sen A. The Idea of Justice. Cambridge, MA: Belknap Press; 2009.

39. Sen A. Well-being, agency and freedom: the Dewey lectures 1984. J Philos. 1985;82(4):169-221.

40. Robeyns I. The Capability Approach: a theoretical survey. J Hum Dev. 2005;6(1):93-117.

41. Loevinger J. Objective tests as instruments of psychological theory. Psychol Rep. 1957;3(9):635-694.

42. Cargo M, Mercer SL. The value and challenges of participatory research: strengthening its practice. Annu Rev Public Health. 2008; 29:325-350.

43. Morgan DL. Focus groups. Annu Rev Sociol. 1996;22:129-152.

44. Pope C, Ziebland S, Mays N. Qualitative research in health care. Analysing qualitative data. BMJ. 2000;320(7227):114-116.

45. Muhr T. ATLAS. ti 6.0. Berlin: Germany: ATLAS ti Scientific Software Development 2009.

46. Weiner SJ, Schwartz A, Weaver F, et al. Contextual errors and failures in individualizing patient care: a multicenter study. Ann Intern Med. 2010;153(2):69-75.

47.Milstein, B. Hygeia's Constellation - Navigating Healthy Futures in a Dynamic and Democratic World. Washington, DC: Centers for Disease Control, Syndemics Prevention Network; 2008.

48. Eyler AA, Baker E, Cromer LC, King AC, Brownson RC, Donatelle RJ. Physical activity and minority women: a qualitative study. Health Educ Behav. 1998;25(5):640-652.

49. Lindsay AC, Sussner KM, Greaney ML, Peterson KE. Influence of social context on eating, physical activity, and sedentary behaviors of Latina mothers and their preschool-age children. Health Educ Behav. 2009;36(1):81-96.

50. Mier N, Medina AA, Ory MG. Mexican Americans with type 2 diabetes: perspectives on definitions, motivators, and programs of physical activity. Prev Chronic Dis. 2007;4(2):A24.

51. Zenk SN, Odoms-Young AM, Dallas $C$, et al. "You have to hunt for the fruits, the vegetables": environmental barriers and adaptive strategies to acquire food in a low-income African American neighborhood. Health Educ Behav. 2011;38(3):282-292. 
52. Yeh MC, Ickes SB, Lowenstein LM, et al. Understanding barriers and facilitators of fruit and vegetable consumption among a diverse multiethnic population in the USA. Health Promot Int. 2008;23(1):42-51.

53. Evenson KR, Sarmiento OL, Tawney KW, Macon ML, Ammerman AS. Personal, social, and environmental correlates of physical activity in North Carolina Latina immigrants. Am J Prev Med. 2003;25(3) (Suppl 1):77-85.

54. King AC, Castro C, Wilcox S, Eyler AA, Sallis JF, Brownson RC. Personal and environmental factors associated with physical inactivity among different racial-ethnic groups of U.S. middle-aged and older-aged women. Health Psychol. 2000;19(4):354-364.

55. French SA, Story M, Jeffery RW. Environmental influences on eating and physical activity. Annu Rev Public Health. 2001;22:309-335.

56. Booth SL, Sallis JF, Ritenbaugh C, et al. Environmental and societal factors affect food choice and physical activity: rationale, influences, and leverage points. Nutr Rev. 2001;59(3 Pt 2):S21-S39, discussion S57-S65.

57. Fisher EB, Brownson CA, O'Toole ML, Shetty G, Anwuri VV, Glasgow RE. Ecological approaches to self-management: the case of diabetes. Am J Public Health. 2005;95(9):1523-1535.
58. Stokols D. Translating social ecological theory into guidelines for community health promotion. Am J Health Promot. 1996;10(4): 282-298.

59. Sallis JF, Cervero RB, Ascher W, Henderson KA, Kraft MK, Kerr J. An ecological approach to creating active living communities. Annu Rev Public Health. 2006;27:297-322.

60. Richard L, Gauvin L, Raine K. Ecological models revisited: their uses and evolution in health promotion over two decades. Annu Rev Public Health. 2011;32:307-326.

61. Woolf SH, Glasgow RE, Krist A, et al. Putting it together: finding success in behavior change through integration of services. Ann Fam Med. 2005;3(Suppl 2):S20-S27.

62. Miller WD, Pollack CE, Williams DR. Healthy homes and communities: putting the pieces together. Am J Prev Med. 2011;40(1)(Suppl 1): S48-S57.

63. Committee on Integrating Primary Care and Public Health, Board on Population Health and Public Health Practice, Institute of Medicine. Primary Care and Public Health: Exploring Integration to Improve Population Health. Washington, DC: National Academies Press; 2012.

\section{CHANGE-OF-ADDRESS FORM FAMNILY MEDICINE}

Please complete this form and mail to the following address or fax to Annals Circulation at 913-906-6080:

Annals of Family Medicine, Circulation Department, 11400 Tomahawk Creek Pkwy, Leawood, KS 66211-2680

Check if member of sponsoring organization:

$$
\begin{array}{ll}
\square \text { AAFP } & \square \text { ABFM } \square \text { STFM } \square \text { ADFM } \\
\square \text { AFMRD } & \square \text { NAPCRG } \square \text { CFPC }
\end{array}
$$

ID number from label on your journal cover

OLD Information (Please print.)

\begin{tabular}{ll}
\hline Name & \\
\hline Company (if applicable) & \\
\hline Address (Street plus Apt or Ste) & State \\
\hline City & Postal Code (9-digit ZIP for US) \\
\hline Country & Fax \\
\hline Telephone & \\
\hline E-Mail
\end{tabular}

NEW Information (Please print.)

\begin{tabular}{ll}
\hline Name & \\
\hline Company (if applicable) & \\
\hline Address (Street plus Apt or Ste) & \\
\hline City & Postal Code (9-digit ZIP for US) \\
\hline Country & \\
\hline Telephone & \\
\hline E-Mail & \\
\hline
\end{tabular}

